\title{
Follow-up of infants with congenital hypothyroidism and low total thyroxine/thyroid stimulating hormone on newborn screen
}

Quinn McCormick, Leslie Pitts, CRNP,

Zachary Hughes, MD

Children's Hospital Alabama, University of Alabama at Birmingham, Birmingham, AL, USA
Received: 5 May, 2019

Revised: 9 June, 2019

Accepted: 14 July, 2019

Address for correspondence:

Zachary Hughes, MD

Northwestern University, Feinberg

School of Medicine, 676 St. Clair

Street, Chicago, IL 60611, USA

Tel: +1-615-557-5217

Fax: +1-205-638-9821

E-mail: zachary.hughes@northwestern. edu

https://orcid.org/0000-0002-09672343
Purpose: Newborn screening (NBS) methods to detect congenital hypothyroidism $(\mathrm{CH})$ vary regarding whether total thyroxine (T4), thyroid stimulating hormone (TSH), or both are measured. Neonates with low T4 and normal or low TSH (lowT4/TSH) may only be detected by T4-inclusive methods or age-dependent repeat screens. Premature neonates and those with pituitary-hypothalamic disorders frequently manifest lowT4/TSH.

Methods: This is a retrospective case-study of newborns who were screen-positive for lowT4/TSH in Alabama in 2009-2016 using a combined T4 and TSH method and 2 routine NBS. The clinical, laboratory, and final diagnosis after 3 years were determined.

Results: Over 8 years, 225 infants were referred to our institution for evaluation and treatment of $\mathrm{CH}$. Twelve infants were screen-positive for lowT4/TSH by first or second NBS. Four of the 12 infants had permanent $\mathrm{CH}$ (30\%): 2 with primary and 2 with central etiologies. One infant with moderately severe central $\mathrm{CH}$ was only detected by the routine second NBS. Six of 7 premature infants had elevated TSH on serum confirmation labs consistent with a delay in hypothalamic-pituitary maturation, yet 2 of these patients were later established to have permanent primary $\mathrm{CH}$. While most cases of lowT4/TSH resolved by 3 years of age, several neonates had extended periods of moderate to severe hypothyroxinemia prior to detection and treatment.

Conclusion: One third of the infants with lowT4/TSH on NBS in this study had permanent $\mathrm{CH}$. These results emphasize the importance of T4-based assay methods, subsequent (repeat) screens and long-term follow-up in the management of neonates with lowT4/TSH on newborn screen.

Keywords: Congenital hypothyroidism, Low T4, Newborn screen

\section{Introduction}

Congenital hypothyroidism $(\mathrm{CH})$ affects between 1:2,000 and 1:3,000 infants worldwide and is a common cause of preventable intellectual disability. ${ }^{1)}$ Neonates with $\mathrm{CH}$ are often asymptomatic and detected by newborn screening (NBS) on whole blood spot samples. Methods for NBS detection and CH diagnosis vary throughout the United States based on the number of screens (1,2 or more) and laboratory assays performed (total thyroxine [T4], thyroid stimulating hormone [TSH], or algorithms for both). Alabama routinely measures both T4 and TSH on all specimens and furthermore obtains 2 newborn screens (at different ages) on over $95 \%$ of babies. Eleven other states also routinely employ a second NBS. ${ }^{2)}$ Several retrospective studies have examined the impact of 2 screen methods for $\mathrm{CH}$ using different lab methods, timing, and study populations, with the most recent reports demonstrating that 
approximately $20 \%$ of new $\mathrm{CH}$ diagnoses are detected by the second screen. $^{3-5)}$

The combination of low T4 with normal to low TSH (lowT4/ $\mathrm{TSH}$ ) in neonates most commonly suggests hypothalamic/ pituitary insufficiency or thyroid binding globulin (TBG) deficiency. Preterm infants have been shown to have a delayed TSH surge due to hypothalamic immaturity that may initially present as lowT4/TSH on NBS. ${ }^{6-8)}$ Of note, follow-up of preterm infants with eutopic thyroid glands has also demonstrated both permanent $\mathrm{CH}$ and persistent hyperthyrotropinemia in many of these neonates. ${ }^{8,9)}$ Central congenital hypothyroidism $(\mathrm{CCH})$ may be detected by NBS; however, it also presents clinically following the newborn period. ${ }^{10,11)}$

As part of a large 8-year study examining the clinical outcome of 225 infants who were screen-positive for $\mathrm{CH}$ in Alabama by the first or second NBS, we observed 12 neonates whose results demonstrated lowT4/TSH. This report presents their clinical description and final diagnosis after 3 years. While common experience suggests that most neonates with lowT4/ TSH on NBS, especially those who are preterm or critically ill, have transient thyroid dysfunction, longitudinal follow-up may uncover a range of permanent hypothyroidism. This situation is especially relevant to neonatal intensive care units (NICU), subspecialty, and primary care practitioners who are tasked with the long-term follow-up care of these babies.

\section{Materials and methods}

\section{Study design}

Twelve infants were identified on NBS with lowT4/TSH. The infants were extracted from a larger retrospective chart review of patients diagnosed with $\mathrm{CH}$ in Alabama between 2009 and 2016. Approximately 472,000 infants were screened over 8 years and over $95 \%$ of screen-positive $\mathrm{CH}$ was referred for evaluation and care at our academic center. As shown in the Fig. 1, 225 patients with $\mathrm{CH}$ were identified (overall prevalence of $\mathrm{CH}$

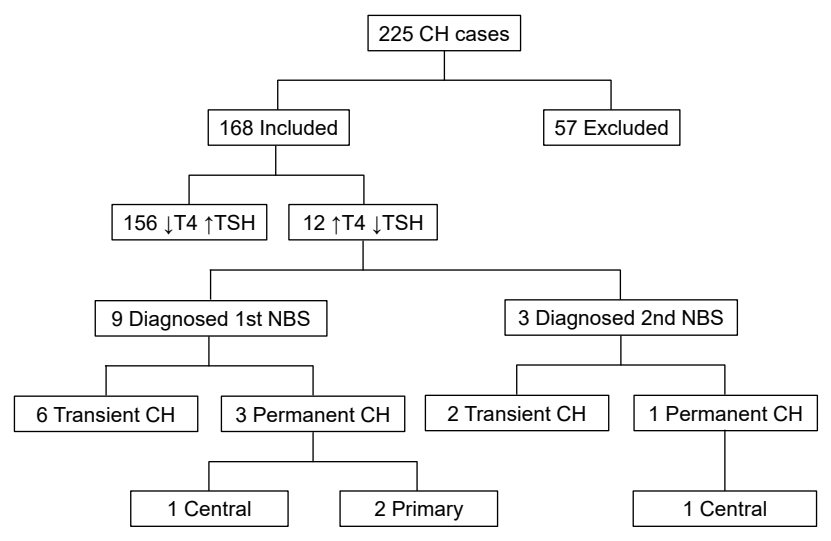

Fig. 1. Patients with congenital hypothyroidism $(\mathrm{CH})$ detected by newborn screen (NBS) in Alabama between 2009 and 2016. T4, total thyroxine; TSH, thyroid stimulating hormone.
1:2100). A total of 168 patients were included for study, and 57 patients were excluded based on the study criteria, the most common being the lack of 2 NBSs for analysis.

Of the 57 excluded patients, 11 were screen-positive with lowT4/TSH and all had normal thyroid ultrasounds. Of these 11 excluded patients, 2 moved out of state and 1 is deceased. Of the remaining 8 patients, 5 were premature (estimated gestational age [EGA], 23-25 weeks): 3 continued 12.5-25 $\mu$ g levothyroxine daily and 2 discontinued treatment with normal follow-up labs. Of the 3 term infants in the excluded group, 1 has $\mathrm{CCH}, 1$ had congenital nephropathy with resolution of hypothyroidism postkidney transplant, and the third infant had TBG deficiency requiring no treatment.

\section{Clinical evaluation and laboratory methods}

In Alabama, the first NBS is usually obtained between 24 and 72 hours of age and the second sample between 1 and 6 weeks of age. In general, $>95 \%$ of all infants undergo 2 screens. For sick or preterm infants, protocols recommend a first NBS on arrival to the NICU, a second NBS at 72 hours, and a third NBS at 2-6 weeks of age. Both total T4 and TSH are measured on all specimens using a time-resolved fluoroimmunoassay (Perkin Elmer Genetic Screening Processor). The normal range for the NBS bloodspot T4 is $76.1-322.5 \mathrm{nmol} / \mathrm{dL}$ and for TSH $<25 \mathrm{mU} / \mathrm{L}$ on all screens. Concerning screen-positive infants who are otherwise well, healthcare providers follow state-wide protocols for repeat testing. For example, if the initial NBS shows low T4/normal TSH, immediate repeat bloodspot for $\mathrm{T} 4 / \mathrm{TSH}$ is recommended. If the repeat is also positive, then serum labs are advised. Prior to treatment, positive screens were confirmed by serum free T4 and TSH using standard commercial labs. The interpretation of diagnostic serum labs depends on many factors, including chronological/gestational age, maternal history, clinical exam and other endocrine labs, medical history and thyroid imaging. We followed consensus recommendations ${ }^{1)}$ and other helpful guidelines ${ }^{12,13)}$ regarding the evaluation and treatment of CH. Specifically, for low free T4/ $\mathrm{TSH}$, we would reconfirm hypothyroxinemia by serial testing every $1-2$ weeks and consider additional clinically-relevant testing of pituitary/hypothalamic function. Thyroid ultrasound (color Doppler) was usually done between 2-4 weeks of age or when $\mathrm{CH}$ was confirmed.

\section{Follow-up diagnosis}

The final diagnosis of the 12 patients was determined by a 3 -month trial discontinuation of levothyroxine at 3 years of age if all TSH values while on treatment were $<10 \mathrm{mU} / \mathrm{L}$. Persistent hyperthyrotropinemia was defined as $\mathrm{TSH}=6-10 \mathrm{mU} / \mathrm{L}$ with normal free T4. ${ }^{1,14)}$ The decision to restart levothyroxine in infants with TSH between 6-8 mU/L (and normal free T4) is especially contestable. ${ }^{15,16)}$ Our approach is to follow serial labs every 3-6 weeks concerning trends as well as the clinical situation (family history, thyroid imaging, growth) prior to 
initiating levothyroxine. If TSH $>10 \mathrm{mU} / \mathrm{L}$ or free $\mathrm{T} 4$ was low, permanent $\mathrm{CH}$ was diagnosed. If any TSH value exceeded 10 $\mathrm{mU} / \mathrm{L}$ while on treatment, the diagnosis of permanent primary hypothyroidism was also confirmed. In contrast, permanent $\mathrm{CCH}$ was defined by low free T4 without an appropriate increase in TSH with consideration of other potential pituitaryhypothalamic insufficiency.

\section{Results}

\section{Patient demographics}

As shown in Table 1, 5 neonates were full term (gestational age $\geq 37$ weeks) while 7 were premature; the premature cases included a set of quadruplets (cases 5-8). The group included 8 males and 4 females; 11 were Caucasian and one infant was African American (case 10). None of the patients had Trisomy 21, other known chromosomal anomalies, or congenital heart disease.

\section{NBS results}

As shown in Table 1, 9 patients (cases 1-9) had low T4 and normal TSH on the first NBS while 3 infants (cases 10-12) had a normal first NBS and abnormal second NBS (also low T4 with normal TSH).

1) Patients detected by 1st NBS (cases 1-9)

Mean values on the first NBS were T4 $=40.0 \pm 11.5 \mathrm{nmol} / \mathrm{L}$ (mean \pm standard deviation) with a range of 23.3 to $54.3 \mathrm{nmol} / \mathrm{L}$ and $\mathrm{TSH}=7.56 \pm 3.37 \mathrm{mU} / \mathrm{L}$ with a range from 2.0 to $11.8 \mathrm{mU} /$
L. The second NBS on these 9 patients revealed hypothyroidism $(\mathrm{T} 4=44.1 \pm 15.5 \mathrm{nmol} / \mathrm{L})$. However, the TSH on this group was elevated in patients 5, 6 and 8 (consistent with the delayed TSH surge of prematurity, mean $\mathrm{TSH}=298 \pm 97 \mathrm{mU} / \mathrm{L}$ ) while the TSH was normal in the remainder of patients (cases 1-4, 7, and 9). Case 7 was on levothyroxine when the second NBS was obtained.

2) Patients detected by 2 nd NBS (cases 10-12)

The first NBS was normal in patients 10-12. The second NBS detected a low T4 $(47.7 \pm 11.6 \mathrm{nmol} / \mathrm{L})$ in concert with a normal mean TSH of $3.2 \pm 0.2 \mathrm{mU} / \mathrm{L}$.

\section{Confirmatory serum labs}

Confirmatory serum labs were obtained on day $32 \pm 15$ in 11 of the 12 patients. One patient, case 11 , had an unusually protracted time to serum diagnosis at 120 days. Based on the serum thyroid values, 7 patients had elevated TSH on serum lab testing (mean serum free T4=7.4 $\pm 3.2 \mathrm{pmol} / \mathrm{L}$ (range, $1.3-10.5$ $\mathrm{pmol} / \mathrm{L}$ ) and mean $\mathrm{TSH}=260 \pm 340 \mathrm{mU} / \mathrm{L}$ (range, $9-957 \mathrm{mU} /$ $\mathrm{L}$ ), while 5 patients continued to have low T4 and normal TSH (mean free T4=7.1 $\pm 1.6 \mathrm{pmol} / \mathrm{L}$ and mean TSH=2.0 $\pm 1.1 \mathrm{mU} / \mathrm{L}$ (range, 1.3-3.6 mU/L) (Table 1).

\section{Thyroid ultrasound}

The thyroid ultrasound was normal in all patients.

\section{Clinical follow-up}

Patients commenced thyroid hormone treatment on average

Table 1. Demographics, thyroid levels, and final diagnosis in patients with $\mathrm{CH}$ detected by newborn screen

\begin{tabular}{|c|c|c|c|c|c|c|c|c|c|c|c|c|c|}
\hline \multirow{2}{*}{$\begin{array}{l}\text { Patient } \\
\text { number }\end{array}$} & \multirow{2}{*}{$\begin{array}{l}\text { EGA } \\
\text { (wk) }\end{array}$} & \multirow{2}{*}{$\begin{array}{l}\text { Birth } \\
\text { weight - } \\
\text { (g) }\end{array}$} & \multicolumn{3}{|c|}{ First newborn screen ${ }^{*}$} & \multicolumn{3}{|c|}{ Second newborn screen ${ }^{\dagger}$} & \multicolumn{3}{|c|}{ Initial serum labs } & \multirow{2}{*}{$\begin{array}{c}\text { Rx } \\
\text { - begun } \\
\text { (day) }\end{array}$} & \multirow{2}{*}{$\begin{array}{c}\text { Final } \\
\text { diagnosis } \\
(\mathrm{CH})\end{array}$} \\
\hline & & & $\begin{array}{l}\text { Age } \\
\text { (day) }\end{array}$ & $\begin{array}{c}\mathrm{T} 4 \text { (nmol/L) } \\
(76.1-322.5)\end{array}$ & $\begin{array}{c}\mathrm{TSH}(\mathrm{mU} / \mathrm{L}) \\
(<25)\end{array}$ & $\begin{array}{l}\text { Age } \\
\text { (day) }\end{array}$ & $\begin{array}{l}\mathrm{T} 4(\mathrm{nmol} / \mathrm{L}) \\
(76.1-322.5)\end{array}$ & $\begin{array}{c}\mathrm{TSH}(\mathrm{mU} / \mathrm{L}) \\
(<25)\end{array}$ & $\begin{array}{l}\text { Age } \\
\text { (day) }\end{array}$ & $\begin{array}{c}\text { Free T4 (pmol/L) } \\
\quad(11.6-18.05)\end{array}$ & $\begin{array}{c}\mathrm{TSH}(\mathrm{mU} / \mathrm{L}) \\
(0.36-6.0)\end{array}$ & & \\
\hline \multicolumn{14}{|c|}{ Diagnosed by first newborn screen } \\
\hline 1 & 37 & 3,799 & 1 & 45.3 & 9.2 & 8 & 46.5 & 3 & 59 & 8.02 & $<0.03$ & 80 & Central \\
\hline 2 & 39 & 3,430 & 2 & 23.3 & 4.2 & 14 & 19.4 & 4.3 & 27 & 9.44 & 2 & 29 & Transient \\
\hline 3 & 31 & 1,505 & 7 & 24.6 & 8.2 & 13 & 41.4 & 13.8 & 17 & 10.47 & 29 & 17 & Transient \\
\hline 4 & 27 & 425 & 1 & 31 & 10.8 & 12 & 32.3 & 8.2 & 79 & 10.09 & 233 & 50 & Transient \\
\hline 5 & 24 & 652 & 1 & 42.7 & 4.9 & 29 & 64.7 & 332 & 24 & 5.17 & 957 & 30 & Transient \\
\hline 6 & 24 & 652 & 1 & 54.3 & 10.5 & 18 & $<20.7$ & 375 & 12 & 1.29 & 559 & 30 & Primary \\
\hline 7 & 24 & 539 & 1 & 47.8 & 6.5 & 33 & 56.9 & 3 & 24 & 8.4 & 23.6 & 24 & Primary \\
\hline 8 & 24 & 539 & 1 & 38.8 & 11.8 & 12 & $<20.7$ & 190 & 24 & 7.24 & 9.9 & 24 & Transient \\
\hline 9 & 37 & 2,863 & 3 & 53 & 2 & 16 & 56.9 & 4.4 & 31 & 6.72 & 1.2 & 31 & Transient \\
\hline \multicolumn{14}{|c|}{ Diagnosed by second newborn screen } \\
\hline 10 & 37 & 3,318 & 2 & 84 & 4.7 & 40 & 49.1 & $<3$ & 56 & 5.17 & 3.6 & 77 & Central \\
\hline 11 & 37 & 3,062 & 2 & 100.9 & 3.1 & 19 & 58.2 & 3.3 & 120 & 9.05 & 9 & 124 & Transient \\
\hline 12 & 24 & 624 & 2 & 95.7 & 12.3 & 28 & 34.9 & 3.4 & 45 & 6.21 & 1.3 & 46 & Transient \\
\hline
\end{tabular}

$\mathrm{CH}$, congenital hypothyroidism; EGA, estimated gestational age; TSH, thyroid stimulating hormone; T4, total thyroxine; free T4, serum thyroxine

"Obtained at $\leq 7$ days after birth. ${ }^{\dagger}$ Obtained between 1 and 6 weeks. ${ }^{\ddagger}$ Final diagnosis after 3 -year follow-up (per methods): Central, central hypothyroidism; Primary, primary hypothyroidism; Transient, trial off levothyroxine at 3 years successful. 
by day 30 of life, except for 3 cases $(1,10$, and 11) in which treatment was much later. Cases 1 and 10 had $\mathrm{CCH}$ and case $11 \mathrm{had}$ an extended period of borderline values (Table 1). All patients were treated with levothyroxine with an average dose $27 \pm 12 \mu \mathrm{g} /$ day for a minimum of 3 years. In the patients with possible $\mathrm{CCH}$, other pituitary hormone deficiencies were excluded.

Based on the final diagnosis criteria (in methods), 2 infants (cases 6 and 7) were diagnosed with permanent primary $\mathrm{CH}$ and 2 infants (cases 1 and 10) had permanent CCH. Case 1 had a small Rathke cyst identified by magnetic resonance imaging while case 10 has not been imaged yet. Abbreviated case descriptions are given in Table 2.

\section{Discussion}

The purpose of NBS for CH is to detect primary hypothyroidism (low T4, high TSH) and initiate levothyroxine treatment to prevent cognitive impairment. Nevertheless, some newborns present with low T4 and normal or low TSH for various reasons, including hypothalamic-pituitary immaturity of the preterm infant, euthyroid sick syndrome, and $\mathrm{CCH}^{17}{ }^{17}$ We identified 12 patients who presented with low T4 and normal TSH on either their first or second NBS. Unique to this report, we present 3-year follow-up information on the final $\mathrm{CH}$ diagnosis. Most noteworthy, 4 of the 12 patients (30\%) were shown to have permanent hypothyroidism, including 2 term infants with $\mathrm{CCH}$ and 2 premature infants with primary $\mathrm{CH}$. Without longitudinal follow-up and treatment, these 4 patients with permanent $\mathrm{CH}$ may have been exposed to a protracted period of hypothyroxinemia.

Preterm infants often have delayed maturation of the hypothalamic-pituitary axis. ${ }^{8}$ By description, there is a lag in the normal postnatal TSH rise such that there is an initial period of low T4 with normal or low TSH, after which the physiologic neonatal TSH surge manifests. In a review of very premature infants (birth weight $<1,499 \mathrm{~g}$ ), Woo et al. noted a mean peak $\mathrm{TSH}=62 \mathrm{mU} / \mathrm{L}$ at 21 days of age with resolution of the TSH surge by 55 days. ${ }^{6}$ Four of the preterm infants in our study (cases 4-6 and 8) developed strikingly high TSH values (TSH range, $190-957 \mathrm{mU} / \mathrm{L}$ ) on either the second NBS and/or serum testing at between 12 and 79 days of age, consistent with a delayed TSH surge. A chart review of these cases confirmed that iodinated radiographic procedures had not been performed before this TSH surge (Table 1). Indeed, in the quadruplets (cases 5-8), urinary iodine levels were low to normal on day 30 of life. Most clinical evidence indicates that premature infants exposed to iodine are at much higher risk of hypothyroidism via an exaggerated Wolff-Chaikoff effect. ${ }^{18)}$ This may be due to increased absorption of iodine by the immature thyroid when exposed to iodine-enriched compounds such as radiographic contrast media. Even though all measured urinary iodine levels were normal in these babies, recent evidence supports that lasting thyroid dysfunction may still be present up to 1 year after

Table 2. Clinical information on case series

\begin{tabular}{|c|c|}
\hline $\begin{array}{l}\text { Patient } \\
\text { number }\end{array}$ & Description \\
\hline 1 & $\begin{array}{l}\text { Height and weight at the 98th \%. MRI of brain normal with small Rathke cleft cyst. Other pituitary endocrine labs normal. Failed trial of } 50 \% \\
\text { dose reduction with low T4 and TSH less than } 0.05 \mathrm{mU} / \mathrm{L} \text {. }\end{array}$ \\
\hline 2 & Normal growth and development. No iodine exposure or maternal thyroid disease. \\
\hline 3 & Patient with 5th percentile growth, history of splenic hemangioma and maternal Hashimoto thyroiditis on treatment during pregnancy. \\
\hline 4 & $\begin{array}{l}\text { Patient with prematurity, pulmonary hypertension and severe developmental delays. Late onset and persistent primary hypothyroidism } \\
\text { with TSH elevations ranging from } 35 \text { to } 233 \mathrm{mU} / \mathrm{L} \text { between days } 45 \text { and } 141 \text { despite commencing levothyroxine on days } 50 \text {. }\end{array}$ \\
\hline 5 & $\begin{array}{l}\text { Quadruplet with NEC and minor bowel perforation. No iodinated contrast media exposure. Urinary iodine at day } 30 \text { was } 0.8 \mu \mathrm{mol} / \mathrm{L} \text { (normal } \\
\text { range, } 0.27-4.13 \mu \mathrm{mol} / \mathrm{L} \text { ). }\end{array}$ \\
\hline 6 & $\begin{array}{l}\text { Quadruplet with history of NEC. lodinated contrast media on days } 57 \text { and } 162 \text {. Urine iodine } 0.18 \\
\mu \mathrm{mol} / \mathrm{L} \text { (normal) on days } 30 \text {. Three-month trial off levothyroxine at age } 3 \text { years led to TSH=10 mU/L }\end{array}$ \\
\hline 7 & $\begin{array}{l}\text { Quadruplet with history of NEC. lodinated contrast media on days } 49 \text { and } 91 . \text { Urinary iodine } 0.44 \\
\mu \mathrm{mol} / \mathrm{L} \text { (normal) on day } 30 . \mathrm{TSH}=9-14 \mathrm{mU} / \mathrm{L} \text { on treatment (age, } 2-5 \text { years) }\end{array}$ \\
\hline 8 & $\begin{array}{l}\text { Quadruplet with history of NEC. lodinated contrast media on day } 63 \text { only. Urinary iodine } 0.5 \mu \mathrm{mol} / \mathrm{L} \text { (normal) on days } 30 \text {. TSH values on } \\
\text { treatment were elevated, day } 101 \mathrm{TSH}=9.3 \mathrm{mU} / \mathrm{L} \text { and on day } 131 \mathrm{TSH}=12.6 \mathrm{mU} / \mathrm{L} \text {. Despite this, thyroid hormone was discontinued at } 3 \\
\text { years of age. }\end{array}$ \\
\hline 9 & $\begin{array}{l}\text { Normal (40th percentile) growth and development. Persistent low T4 and free T4. Normal pituitary endocrine evaluation. No maternal } \\
\text { thyroid disease or iodine exposure. Normal eye exam. }\end{array}$ \\
\hline 10 & $\begin{array}{l}\text { Normal (70th percentile) growth and development. Persistent low free T4 and TSH. Unadvised trial off levothyroxine at } 1.8 \text { years of life for } 3 \\
\text { months led to low freeT4=7.74 pmol/L (11.5-17.7), low T4 free direct dialysis=7.70 pmol/L (15.5-32.2), low T3=1.64 nmol/L (1.8-3.7), with } \\
\text { inappropriately low TSH=0.99 mU/L (normal, 0.7-4.17). Normal cortisol and IGF-1. No vision or developmental concerns. }\end{array}$ \\
\hline 11 & $\begin{array}{l}\text { Normal growth and development, mild jaundice. Between } 1 \text { and } 4 \text { months of age, free T4 decreased from } 19.4 \text { to } 9.0 \text { pmol/L (11.5-17.7) } \\
\text { and TSH increased from } 6 \text { to } 9 \mathrm{mU} / \mathrm{L} \text { (levothyroxine started). No iodine exposure or maternal thyroid disease. }\end{array}$ \\
\hline 12 & $\begin{array}{l}\text { History of bronchopulmonary dysplasia, NEC, and grade } 2 \text { intraventricular hemorrhage. Prolonged low T4/TSH. No other pituitary- } \\
\text { hypothalamic endocrine dysfunction. }\end{array}$ \\
\hline
\end{tabular}


iodine exposure. ${ }^{19)}$

Of note, 2 of the quadruplets (cases 6 and 7), who initially appeared to have a prematurity-related delayed TSH surge, were subsequently shown to have permanent primary $\mathrm{CH}$. Their TSH values on or off levothyroxine ranged from 9 to $14 \mathrm{mU} / \mathrm{L}$ with normal free T4. This phenomenon was also observed by Cuestas et al. $^{20)}$ concerning persistent neonatal hyperthyrotropinemia. Recently, McGrath et al. ${ }^{9)}$ also confirmed the importance of long-term follow-up of these preterm infants, noting $22 \%$ with permanent $\mathrm{CH}$. One of the remaining 6 premature infants in our study (case 12) demonstrated persistently low T4/ TSH for 46 days of life before levothyroxine was started. This infant was not exposed to dopamine but had intermittent glucocorticoids, both of which suppress thyroid function.

Of the 2 infants diagnosed with $\mathrm{CCH}$ (cases 1 and 10), case 1 had an isolated TSH deficiency and a small Rathke cleft cyst, a malformation that has been associated with pediatric pituitary dysfunction. ${ }^{21)}$ Case 10 has not yet undergone pituitary imaging. Of importance, both cases with $\mathrm{CCH}$ in this study had initial serum free $\mathrm{T} 4$ in the moderately severe $\mathrm{CH}$ range of $4.38-10.0 \mathrm{pmol} / \mathrm{L}^{1)}$ and were not treated until 11 weeks of age, observations that emphasize the importance for early detection. $^{11)}$

Central $\mathrm{CH}$ has an incidence in 1:20,000 using screening algorithms that measure T4 in concert with TBG and TSH. However, earlier reports suggest prevalence rates closer to $1: 100,000{ }^{22)}$ One study using T4/free T4 and TSH noted a $\mathrm{CCH}$ prevalence of 1:160,000, while another using T4 $(<58.0$ $\mathrm{nmol} / \mathrm{L})$ and TSH $(<10 \mathrm{mU} / \mathrm{L})$ noted central $\mathrm{CH}$ in $1: 23,000$. Not unexpectedly, detection rates will be diminished in NBS programs that are TSH-based. ${ }^{17)}$ Concerning this study, it should be mentioned that one additional case of $\mathrm{CCH}$ was excluded from our study cohort because full data on both the 1st and 2nd NBS were missing. If included, 3 cases of permanent $\mathrm{CCH}$ were detected by NBS per 472,000 infants screened, yielding a prevalence of $\mathrm{CCH}$ of 1:157,000. Clinical evidence supports, however, that most cases of $\mathrm{CCH}$ are diagnosed clinically rather than by NBS. ${ }^{10)}$

Three of the patients in this review were NBS-positive for low T4 and normal TSH on the 2nd NBS. Case 12 was an extremely premature infant with persistently low serum free T4 and TSH values (levothyroxine treatment on day 78) who was eventually shown to have transient $\mathrm{CH}$. This patient was not treated with dopamine, but had intermittent glucocorticoids for lung disease. This clinical scenario is an ongoing challenge in the NICU, in which the complexity of care predisposes infants to euthyroid sick syndrome and exposure to agents such as dopamine and glucocorticoids, both of which can suppress pituitary-hypothalamic function. ${ }^{23)}$ Case 11 had a forme fruste prolonged period of low free T4 with normal TSH but eventually developed an elevated $\mathrm{TSH}=9 \mathrm{mU} / \mathrm{L}$ at 4 months of age consistent with primary hypothyroidism (Table 1). Why this otherwise healthy term infant did not mount an earlier TSH response to her progressive hypothyroidism is unclear, although subtle resolving hypothalamic/pituitary insufficiency is possible. ${ }^{24)}$ In addition, there was no history of maternal hypothyroidism, siblings with $\mathrm{CH}$, or iodine exposure in this infant. The third case diagnosed by 2 nd NBS was a term baby (case 10) with $\mathrm{CCH}$ (discussed previously).

Case 3 is instructive for having 3 conceivable reasons for neonatal thyroid dysfunction, namely, prematurity, maternal thyroid disease on treatment, and multiple hemangiomas. This baby was born at 1,500 g; hence, a delayed TSH surge was less likely compared to more premature infants $(<1,499$ g). ${ }^{6}$ Maternal autoimmune hypothyroidism can be associated with blocking antibodies that induce a transient primary $\mathrm{CH}$. The delayed onset at 17 days of age and ultimate diagnosis of transient $\mathrm{CH}$ could plausibly be a result of these antibodies. Thyroid blocking antibodies were not measured. Several cases of transient $\mathrm{CH}$ caused by infantile hemangiomas containing thyroid deiodinase have also been described. Thyroid deiodinase inactivates $\mathrm{T} 4$ by converting it to reverse $\mathrm{T} 3$, which is an inert form of the hormone. Thus, the multiple hemangiomas seen in this case could have been a cause of this infant's transient $\mathrm{CH}^{25,26)}$ While an exact cause for this infant's transient $\mathrm{CH}$ was not determined, it demonstrates the potential pathophysiologic complexity of neonatal thyroid dysfunction.

In summary, lowT4/TSH was identified by NBS in a cohort of 12 infants, all of whom were referred for evaluation and treatment of $\mathrm{CH}$. While all infants had normal thyroid glands by ultrasound, 4 had permanent $\mathrm{CH}$ after 3 years of follow-up. Concerning the recognized TSH surge of premature infants that is most often associated with transient $\mathrm{CH}, 2$ of the 7 premature infants in this study with this delayed TSH surge had permanent $\mathrm{CH}$. These results highlight the fundamental importance of following neonates with lowT4/TSH whose potential thyroid dysfunction ranges from transient hypothalamic/pituitary insufficiency to significant primary and central hypothyroidism requiring long-term treatment. This concern is heightened by reports ${ }^{20)}$ demonstrating that even transient neonatal thyroid dysfunction may have long-term adverse developmental repercussions.

\section{Conflict of interest}

No potential conflict of interest relevant to this article was reported.

\section{Ethical statement}

Institutional Review Board of University of Alabama at Birmingham (IRB-151104007) approval was obtained for this retrospective review of patient medical records with waiver of informed consent.

\section{References}

1. Léger J, Olivieri A, Donaldson M, Torresani T, Krude $\mathrm{H}$, van Vliet G, et al. European Society for Paediatric Endocrinology consensus guidelines on screening, 
diagnosis, and management of congenital hypothyroidism. J Clin Endocrinol Metab 2014;99:363-84.

2. Shapira SK, Hinton CF, Held PK, Jones E, Harry Hannon W, Ojodu J. Single newborn screen or routine second screening for primary congenital hypothyroidism. Mol Genet Metab 2015;116:125-32.

3. Ford GA, Denniston S, Sesser D, Skeels MR, LaFranchi SH. Transient versus permanent congenital hypothyroidism after the age of 3 years in infants detected on the first versus second newborn screening test in Oregon, USA. Horm Res Paediatr 2016;86:169-77.

4. Jones DE, Hart K, Shapira SK, Murray M, Atkinson-Dunn $\mathrm{R}$, Rohrwasser A. Identification of primary congenital hypothyroidism based on two newborn screens - Utah, 2010-2016. MMWR Morb Mortal Wkly Rep 2018;67:7825.

5. Kilberg MJ, Rasooly IR, LaFranchi SH, Bauer AJ, Hawkes CP. Newborn screening in the US may miss mild persistent hypothyroidism. J Pediatr 2018;192:204-8.

6. Woo HC, Lizarda A, Tucker R, Mitchell ML, Vohr B, Oh W, et al. Congenital hypothyroidism with a delayed thyroidstimulating hormone elevation in very premature infants: incidence and growth and developmental outcomes. J Pediatr 2011;158:538-42.

7. Zung A, Yehieli A, Blau A, Almashanu S. Characteristics of Delayed thyroid stimulating hormone elevation in neonatal intensive care unit newborns. J Pediatr 2016;178:135-40.e1.

8. Vigone MC, Caiulo S, Di Frenna M, Ghirardello S, Corbetta C, Mosca F, et al. Evolution of thyroid function in preterm infants detected by screening for congenital hypothyroidism. J Pediatr 2014;164:1296-302.

9. McGrath N, Hawkes CP, Mayne P, Murphy NP. Optimal timing of repeat newborn screening for congenital hypothyroidism in preterm infants to detect delayed thyroid-stimulating hormone elevation. J Pediatr 2019;205:77-82.

10. Nebesio TD, McKenna MP, Nabhan ZM, Eugster EA. Newborn screening results in children with central hypothyroidism. J Pediatr 2010;156:990-3.

11. Zwaveling-Soonawala N, van Trotsenburg AS, Verkerk PH. The severity of congenital hypothyroidism of central origin should not be underestimated. J Clin Endocrinol Metab 2015;100:E297-300.

12. Connelly KJ, LaFranchi SH. Detection of neonates with mild congenital hypothyroidism (primary) or isolated hyperthyrotropinemia: an increasingly common management dilemma. Expert Rev Endocrinol Metab 2014;9:26371.

13. LaFranchi SH. Approach to the diagnosis and treatment of neonatal hypothyroidism. J Clin Endocrinol Metab
2011;96:2959-67.

14. American Academy of Pediatrics, Rose SR; Section on Endocrinology and Committee on Genetics, American Thyroid Association, Brown RS; Public Health Committee, Lawson Wilkins Pediatric Endocrine Society, Foley T, et al. Update of newborn screening and therapy for congenital hypothyroidism. Pediatrics 2006;117:2290-303.

15. Schushan-Eisen I, Lazar L, Amitai N, Meyerovitch J. Thyroid functions in healthy infants during the first year of life. J Pediatr 2016;170:120-5.e1.

16. Wassner AJ, Brown RS. Subclinical hypothyroidism in infancy: to treat or not to treat, that is the question. J Pediatr 2016;170:17-9.

17. Braslavsky D, Méndez MV, Prieto L, Keselman A, Enacan R, Gruñeiro-Papendieck L, et al. Pilot neonatal screening program for central congenital hypothyroidism: evidence of significant detection. Horm Res Paediatr 2017;88:27480 .

18. Ahmet A, Lawson ML, Babyn P, Tricco AC. Hypothyroidism in neonates post-iodinated contrast media: a systematic review. Acta Paediatr 2009;98:1568-74.

19. Barr ML, Chiu HK, Li N, Yeh MW, Rhee CM, Casillas J, et al. Thyroid dysfunction in children exposed to iodinated contrast media. J Clin Endocrinol Metab 2016;101:236670 .

20. Cuestas E, Gaido MI, Capra RH. Transient neonatal hyperthyrotropinemia is a risk factor for developing persistent hyperthyrotropinemia in childhood with repercussion on developmental status. Eur J Endocrinol 2015;172:483-90.

21. Lim HH, Yang SW. Risk factor for pituitary dysfunction in children and adolescents with Rathke's cleft cysts. Korean J Pediatr 2010;53:759-65.

22. Schoenmakers N, Alatzoglou KS, Chatterjee VK, Dattani MT. Recent advances in central congenital hypothyroidism. J Endocrinol 2015;227:R51-71.

23. Van den Berghe G, de Zegher F, Lauwers P. Dopamine suppresses pituitary function in infants and children. Crit Care Med 1994;22:1747-53.

24. Tonyushkina KN, Krug S, Ortiz-Toro T, Mascari T, Karlstrom RO. Low thyroid hormone levels disrupt thyrotrope development. Endocrinology 2017;158:2774-82.

25. Huang SA, Tu HM, Harney JW, Venihaki M, Butte AJ, Kozakewich HP, et al. Severe hypothyroidism caused by type 3 iodothyronine deiodinase in infantile hemangiomas. N Engl J Med 2000;343:185-9.

26. Luongo C, Trivisano L, Alfano F, Salvatore D. Type 3 deiodinase and consumptive hypothyroidism: a common mechanism for a rare disease. Front Endocrinol (Lausanne) 2013;4:115. 